\title{
Experiential Learning Design of E-Learning Website
}

\author{
Sasmoko $^{1 *}$, Yogi Udjaja ${ }^{2}$, Yasinta Indrianti ${ }^{3}$, Xiao Xiang Zhong ${ }^{4}$, Abu Yazid Abu Bakar \\ ${ }^{1}$ Primary Teacher Education Department, Faculty of Humanities, Bina Nusantara University, Jakarta, Indonesia, 11480 \\ ${ }^{2}$ Computer Science Department, School of Computer Science, Bina Nusantara University, Jakarta, Indonesia 11480 \\ ${ }^{3}$ Research Interest Group in Educational Technology, Bina Nusantara University, Jakarta, Indonesia 11480 \\ ${ }^{4}$ Fujian Normal University, China \\ ${ }^{5}$ Faculty of Education, Universiti Kebangsaan Malaysia, 43600 Bangi, Selangor, Malaysia \\ *Corresponding author. Email: sasmoko@binus.edu
}

\begin{abstract}
The 4.0 industry revolution needed to change the revolution in higher education which is characterized by increased literacy and self-transformation so that there is an effort to maximize blended learning. This effort will give a positive result because it can provide a pleasant learning experience through experiential learning. This research tries to build constructs through website sasmoko.com to present experiential learning through e-learning as an effort to meet the needs of today's students who belong to a millennial generation with the main character is highly integrated with technological progress. The method used are moonshot thinking, computer assisted education, gamification and challange-based learning. The result of the research is the utilization of website sasmoko.com for e-learning so as to accommodate the needs of students in learning and facilitate and facilitate lecturers in delivering information online.
\end{abstract}

Keywords: Experiential learning, e-learning, website, sasmoko.com

\section{INTRODUCTION}

The 4.0 industry revolution is characterized by a collaboration between traditional industry forces and the development of modern technology that allows the integration of smart products into digital and physical industrial processes (Schmidt, 2015). This change also changed the business processes that exist in college. Previously, instructional technology had a significant impact on teaching, research and community service in college (Surry et al., 2005). The use of blended learning is one approach that is sufficiently able to integrate technology into pedagogy, with a general statement describing the condition through the term digital learning environment or computer learning environment where the learning process is focused on the delivery of information (Georgina \& Olson, 2008).

Higher education is a part of education, where there are efforts and plans to create an atmosphere and learning process so as to develop the potential of students and students to be useful for students and students, as well as for society, nation and country (Udjaja et al., 2018). With the advancement of technology at this time it is time college participate improve teaching and learning process in accordance with the needs of millennial generation. A common characteristic of millennial generation is the ability to adapt to new technologies and new equipment quickly enough. They are very enthusiastic about instant messaging, videogames and file sharing (Godwin-Jones, 2005).

Based on the survey of students and college students now requires flexibility to the learning that can be done anywhere and anytime without reducing the quality of learning face-to-face. To achieve this, created a website that has the potential as a medium of learning that can be accessed anywhere and anytime. This research tries to present experiential learning implementation on website sasmoko.com, which is a concept where the tools and techniques provided provide a comprehensive learning experience for the users so that it can be utilized by lecturers and students through a website (Kolb \& Kolb, 2005).

\section{METHODS}

Changes in the generation and rapid development of technology have various implications especially in the learning and training process. The most important thing is how to integrate various approaches that focus on the needs of the present generation so as to fulfill their commitment to growth and success (Robert \& Newsline, 2005).

Experiential learning is a method that can attract a person's attention in terms of learning, so that the person can learn actively and can create a conducive learning experience, and produce specific scientific improvements, as studied (Ozogul, 2018). It also affects 
the emotional and affective users, who are appointed based on the art of product design planning on interaction with users (Kristiadi et al., 2017).

In experiential learning, some methods are needed to support the objectives that are in line with the current industry revolution.

\section{Moonshot Thinking}

Moonshot Thinking operates with current problems and provides radical solutions, then utilizes some preliminary validation or breakthroughs that can make the solution less time-consuming (Knight, 2018).

\section{Computer Assisted Education}

With the existence of computer-assisted education, activities related to education become more effective and efficient (Ozdemir, 2017). It can also facilitate learning conditions, where with science transferred through technology, learning can be done anywhere, as well as more challenged users to use it. Science is transferred using an expert system, where the scholarship of an expert is used as the content of learning (Udjaja, 2018).

\section{Gamification}

Gamification, in this case, is used to attract attention and provide motivation to the user, in order to improve the effectiveness of the learning function or the contribution of knowledge contained in technology (Yanfi et al., 2018; Udjaja, 2018).

\section{Challenge-Based Learning}

Challenge-Based Learning (CBL) is an approach used for educational revolution which encourages technology users to actively learn with anyone in accordance with predetermined categories (Kohn et al., 2018).

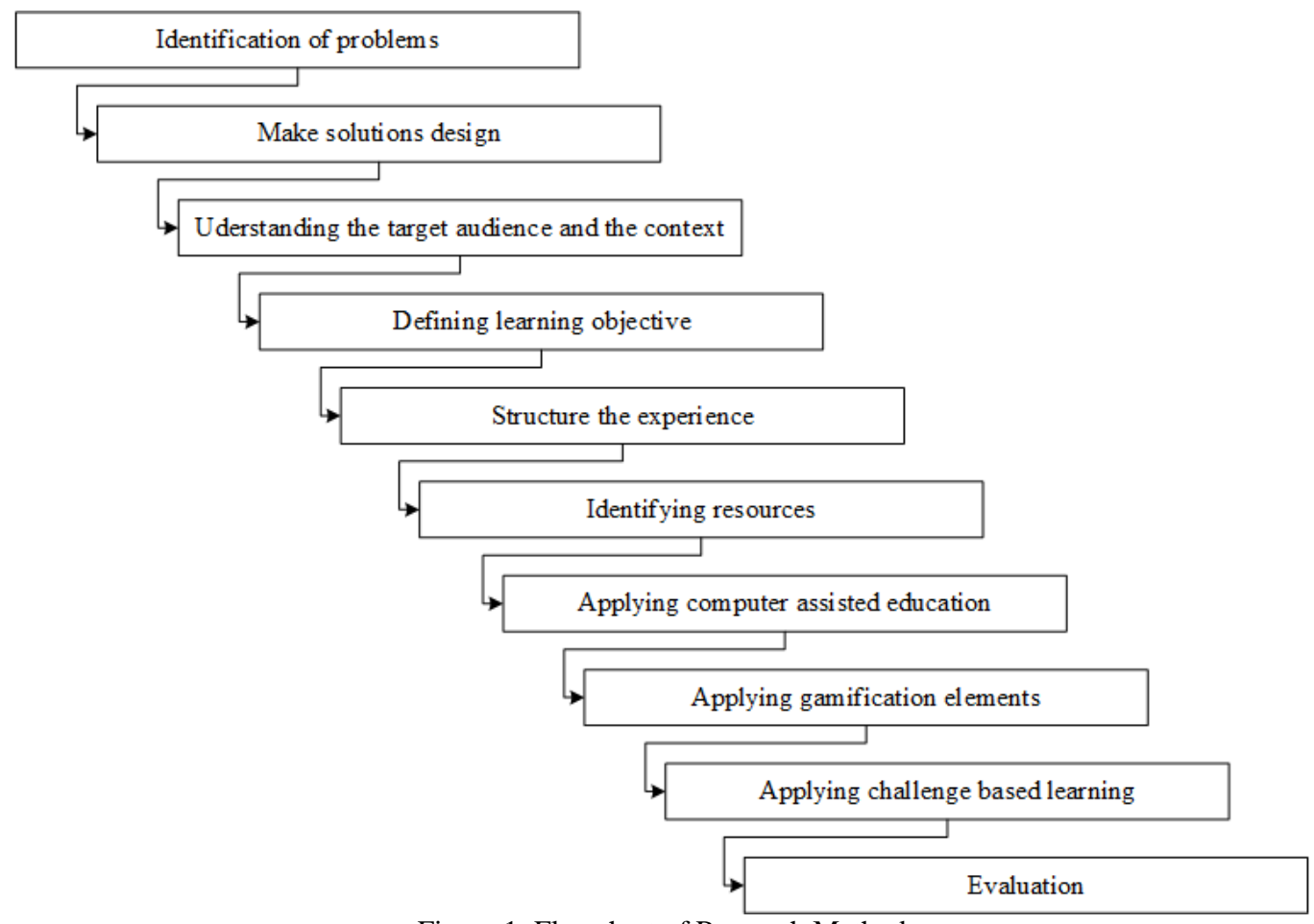

Figure 1: Flowchart of Research Method

\section{RESULTS AND ANALYSIS}

Table 1: E-Learning User Value Result from Website Sasmoko.com

\begin{tabular}{|c|c|c|c|c|c|c|c|c|c|c|c|}
\hline No & Student ID & Value & No & Student ID & Value & No & Student ID & Value & No & Student ID & Value \\
\hline 1 & 2110440 & 84.67 & 42 & 10021002 & 46.67 & 83 & 1401136960 & 93.33 & 124 & 1901526722 & 86.67 \\
\hline 2 & 2110457 & 70.00 & 43 & 10021004 & 58.00 & 84 & 1501169650 & 80.67 & 125 & 2001549986 & 49.33 \\
\hline 3 & 2110462 & 68.00 & 44 & 10021005 & 76.67 & 85 & 1501170381 & 52.67 & 126 & 2001553296 & 79.33 \\
\hline 4 & 2110474 & 92.00 & 45 & 10021006 & 58.00 & 86 & 1501181366 & 68.00 & 127 & 2001554241 & 87.33 \\
\hline 5 & 2111483 & 58.67 & 46 & 10021012 & 58.00 & 87 & 1501205750 & 72.00 & 128 & 2001554310 & 84.00 \\
\hline
\end{tabular}




\begin{tabular}{|c|c|c|c|c|c|c|c|c|c|c|c|}
\hline 6 & 2111495 & 88.00 & 47 & 10021016 & 89.33 & 88 & 1601211754 & 88.67 & 129 & 2001578531 & 70.00 \\
\hline 7 & 2111524 & 74.00 & 48 & 10091005 & 84.67 & 89 & 1601211773 & 93.33 & 130 & 2001586823 & 94.00 \\
\hline 8 & 2112499 & 98.67 & 49 & 10091006 & 77.87 & 90 & 1601211786 & 66.67 & 131 & 2001587605 & 69.33 \\
\hline 9 & 2112501 & 77.33 & 50 & 10091007 & 88.93 & 91 & 1601225255 & 88.00 & 132 & 2001588053 & 94.67 \\
\hline 10 & 2112508 & 96.00 & 51 & 10091008 & 53.27 & 92 & 1601231642 & 83.33 & 133 & 2001588131 & 42.00 \\
\hline 11 & 2112514 & 98.67 & 52 & 10091009 & 57.80 & 93 & 1601239506 & 55.33 & 134 & 2001588564 & 88.67 \\
\hline 12 & 2112515 & 98.67 & 53 & 10091011 & 82.67 & 94 & 1601241920 & 78.00 & 135 & 2001588690 & 46.67 \\
\hline 13 & 2112517 & 92.00 & 54 & 10091014 & 62.00 & 95 & 1601243516 & 94.67 & 136 & 2001588822 & 73.33 \\
\hline 14 & 2112520 & 60.00 & 55 & 10091017 & 82.00 & 96 & 1601244916 & 47.33 & 137 & 2001591041 & 69.33 \\
\hline 15 & 2112520 & 86.67 & 56 & 10091019 & 84.53 & 97 & 1601245591 & 62.67 & 138 & 2001598161 & 84.00 \\
\hline
\end{tabular}

Table 2: Confidence Interval of Student understanding Using E-learning

\begin{tabular}{|c|c|c|c|c|c|c|c|c|c|c|c|}
\hline No & Student ID & Value & No & Student ID & Value & No & Student ID & Value & No & Student ID & Value \\
\hline 16 & 2112524 & 86.67 & 57 & 10091022 & 82.67 & 98 & 1601248006 & 7.33 & 139 & 2001601515 & 88.00 \\
\hline 17 & & .33 & 58 & 10091024 & 67 & 99 & 601248574 & 5.67 & 140 & & 5.33 \\
\hline 18 & & 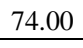 & 59 & & 5.33 & 100 & & 68.67 & 141 & & 78.00 \\
\hline 19 & 2113527 & 53.33 & 60 & 10091027 & 0.13 & 101 & 1601258215 & 74.00 & 142 & 2001607550 & 65.33 \\
\hline 20 & 2113532 & 81.33 & 61 & 10091029 & 2.67 & 102 & 1601259956 & 87.33 & 143 & 2001610526 & 82.67 \\
\hline 21 & & 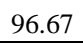 & 62 & 10091032 & 89.00 & 103 & 1601261815 & 83.33 & 144 & & 81.33 \\
\hline 22 & 13545 & 82.00 & 63 & 10091038 & 67.87 & 104 & 1601271886 & 93.33 & 145 & 2001622463 & 70.00 \\
\hline 23 & 2113546 & 86.67 & 64 & 10091043 & 62.33 & 105 & 1601271892 & 68.00 & 146 & 2001626713 & 42.00 \\
\hline 24 & 2113548 & 95.33 & 65 & 10091044 & 80.13 & 106 & 1601277031 & 74.67 & 147 & 10010310030 & 68.00 \\
\hline 25 & 14550 & 86.67 & 66 & 10091046 & 73.53 & 107 & 1601278482 & 88.67 & 148 & 11010310001 & 72.67 \\
\hline 26 & 4555 & 95.33 & 67 & 10091047 & 89.00 & 108 & 1601279440 & 62.00 & 149 & 11010310004 & 80.00 \\
\hline 27 & 2114559 & 98.00 & 68 & 12011001 & 93.33 & 109 & 1601285235 & 92.67 & 150 & 11010310010 & 76.67 \\
\hline 28 & 2114560 & 95.33 & 69 & 12011002 & 59.33 & 110 & 1601286130 & 81.33 & 151 & 11010310013 & 49.33 \\
\hline 29 & & 69.33 & 70 & & & & & & 152 & & 93.33 \\
\hline 30 & 2210431 & 46.67 & 71 & 12011005 & 69.33 & 112 & 1601288306 & 58.67 & 153 & 11010310023 & 99.33 \\
\hline 31 & 2212507 & 92.00 & 72 & 12011006 & 82.67 & 113 & 1901499532 & 74.00 & 154 & 11010310026 & 66.67 \\
\hline 32 & 3456 & 98.67 & 73 & 12011007 & & & 1901502086 & & 155 & 11010310034 & 68.00 \\
\hline 33 & 2213462 & 96.67 & 74 & 12012013 & 88.33 & 115 & 1901502786 & 84.00 & 156 & 11010310038 & 44.67 \\
\hline 34 & 3111087 & 55.33 & 75 & 12012013 & 88.33 & 116 & 1901503233 & 90.67 & 157 & 11010310044 & 80.00 \\
\hline 35 & 3112091 & 54.00 & 76 & 12012016 & & 117 & 1901510296 & 67.33 & 158 & 11010310046 & 92.00 \\
\hline 36 & 3112095 & 52.67 & 77 & 12022003 & 88.33 & 118 & 1901512805 & 68.67 & 159 & 11010310047 & 59.33 \\
\hline 37 & 3113096 & 96.67 & 78 & 31100889 & 64.00 & 119 & 1901512843 & 50.67 & 160 & 11010310049 & 65.33 \\
\hline 38 & & 66.00 & 79 & & & 120 & & & 161 & & 63.33 \\
\hline 39 & 10011001 & 92.00 & 80 & 1010310029 & 66.67 & 121 & 1901512875 & 80.67 & 162 & 11010310073 & 90.00 \\
\hline 40 & 10011003 & 62.00 & 81 & 1301053175 & 88.67 & 122 & 1901514470 & 94.00 & 163 & 12010310009 & 78.00 \\
\hline 41 & 10011006 & 94.00 & 82 & 1401135384 & 56.67 & 123 & 1901520460 & 83.33 & 164 & 20121350106 & 80.00 \\
\hline
\end{tabular}


Descriptives

\begin{tabular}{|c|c|c|c|c|}
\hline & & & Statistic & Std. Error \\
\hline \multirow[t]{13}{*}{ ELearn_Cog-Y } & \multicolumn{2}{|l|}{ Mean } & 76.5757 & 1.14430 \\
\hline & \multirow{2}{*}{$\begin{array}{l}95 \% \text { Confidence Interval } \\
\text { for Mean }\end{array}$} & Lower Bound & 74.3161 & \\
\hline & & Upper Bound & 78.8352 & \\
\hline & \multicolumn{2}{|l|}{$5 \%$ Trimmed Mean } & 77.0902 & \\
\hline & \multicolumn{2}{|l|}{ Median } & 80.0000 & \\
\hline & \multicolumn{2}{|l|}{ Variance } & 214.746 & \\
\hline & \multicolumn{2}{|l|}{ Std. Deviation } & 14.65421 & \\
\hline & \multicolumn{2}{|l|}{ Minimum } & 42.00 & \\
\hline & \multicolumn{2}{|l|}{ Maximum } & 99.33 & \\
\hline & \multicolumn{2}{|l|}{ Range } & 57.33 & \\
\hline & \multicolumn{2}{|l|}{ Interquartile Range } & 21.66 & \\
\hline & \multicolumn{2}{|l|}{ Skewness } & -.436 & 190 \\
\hline & \multicolumn{2}{|l|}{ Kurtosis } & -.776 & 377 \\
\hline
\end{tabular}

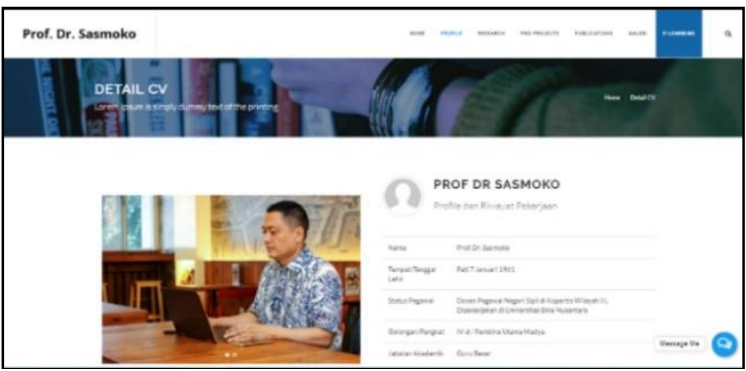

Figure 2: Front-end E-Learning Website Sasmoko.com

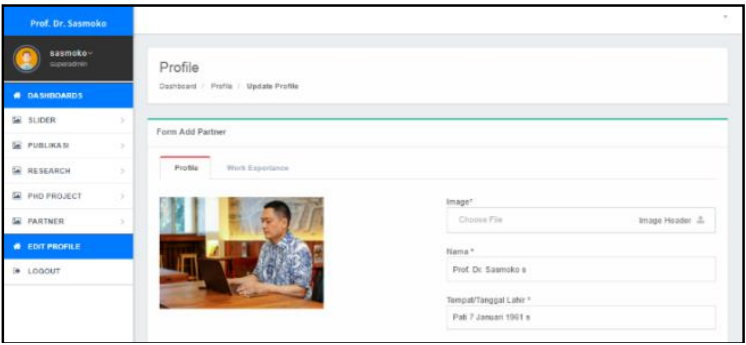

Figure 3: Back-end E-Learning Website Sasmoko.com

This website creation stage begins with thinking of the idea of becoming the solution of the problem, then the solution is made to support the lectures assisted by the expert system as the transfer of knowledge from the experts into the technology and using gamification and CBL so that users feel motivated and challenged to learn in any circumstances. The results of the design model can be seen in figures 2 and 3 .

Stages of e-learning database access website sasmoko.com can be seen in figure 4. The figure explains the flow of the administrator to make the material, make a problem, make corrections until the user to register the website to access the material and do the quiz answers submission.

Based on the results of testing for 6 months from 164 students or students the average learning outcomes from website sasmoko.com is $76.57 \%$, where there is an increase in the user's knowledge from $42 \%-99.33 \%$ (See table 1)
In proving the success of e-learning as a complement of learning, the researcher establishes 5 (five) categories of student understanding: (a) very bad, (b) not good, (c) sometimes good, sometimes not good, (d) good, and (e) very good. Data analysis was done with a confidence interval at significance level 5\% and produced lower and upper boundary between 74,3161 up to 78,8352 (see figure 5). Based on the results of the analysis, it can be concluded that students who use e-learning sasmoko.com tend to have a good understanding significantly at $\alpha$ $<0.05$.

\section{DISCUSSION AND CONCLUSIONS}

Each stage based on the research method has covered all experiential learning required. Where the development of technology is directly proportional to the development of education. This can be seen in the website system created and the enhancement of the specific capabilities of the user. The improvement depends on the psychological aspects of a person and the high level of one's learning.

Some aspects of psychology that support the improvement of learning in the context of technological progress are:

- Student Engagement

Utilization of computer games as one means of learning has been able to show an increase in student engagement because they as a generation who are familiar with the technology is able to use in a relatively long time. This, when combined with challenging tasks and requiring deep concentration, will increase their absorption of the learning process undertaken. The concept of engagement became a concept in game-based learning research (Hamari, 2016).

- Student Satisfaction

Headings, or heads, are organizational devices that guide the Online learning is sufficient to assist students in exploring widely their learning spaces. in a study found the existence of three components of fundamental satisfaction that is engaged learning, agency and assessment (Dziuban, 2015).

- Self-Regulated Learning

Independent learning is a major factor underlying the success of online learning because it is able to control themselves academically and emotionally so that it can automatically be applied in an independent learning process. A study exploring the association between academic emotions in learning was able to facilitate independent learning and other studies proved that will control was identified as one of the important constituents of this success (You \&kang, 2014; Kizilcec\&Halawa, 2015).

The future of technology maintenance will be evaluated using user experience and other testing methods as each technology will require development to 
adapt to the increasingly complex needs of users. In the next stage of development, researchers will apply neuroresearch methods to enrich and deepen experiential learning studies to be more applicable for users. This research method will further maximize the integration of technology that is done because it is supported by three important stages, namely exploratory research that helps researchers to more up to date with studies of various scientific developments as appropriate, explanatory research as the testing stage for the development and confirmatory research so that researchers obtain clear confirmation of the validity and reliability of the development undertaken.

\section{ACKNOWLEDGMENTS}

This work is partially supported by Inixindo's Mentors, Yasib Abdi Polela, the students who helped develop the quiz system, Prof. Dr. Gerald Pola, M.Sc and Binus University. The authors also gratefully acknowledge the helpful comments and suggestions of the reviewers, which have improved the presentation.

\section{REFERENCES}

Dziuban, C., Moskal, P., Thompson, J., Kramer, L., DeCantis, G., \& Hermsdorfer, A. (2015). Student Satisfaction with Online Learning: Is It a Psychological Contract?. Online Learning, 19(2), n2.

Georgina, D. A., \& Olson, M. R. 2008. Integration of technology in higher education: A review of faculty self-perceptions. The Internet and Higher Education, 11(1), 1-8.

Godwin-Jones, R. 2005. Messaging, gaming, peer-to-peer sharing: Language learning strategies \& tools for the millennial generation.

Hamari, J., Shernoff, D. J., Rowe, E., Coller, B., Asbell-Clarke, J., \& Edwards, T. 2016. Challenging games help students learn: An empirical study on engagement, flow and immersion in game-based learning. Computers in Human Behavior, 54, 170-179.

Kizilcec, R. F., \& Halawa, S. 2015. Attrition and achievement gaps in online learning. In Proceedings of the Second (2015) ACM Conference on Learning@ Scale (pp. 5766). ACM.

Kristiadi, D. P., Udiaia, Y., Supangat, B., Prameswara, R. Y., Warnars, H. L. H. S., Heryadi, Y., \& Kusakunniran, W. 2017. The effect of UI, UX and GX on video games. In Cybernetics and Computational Intelligence (CvberneticsCom), 2017 IEEE International Conference on (pp. 158-163). IEEE.

Knight, P. T. 2018. Sufficiency, Sustainability, and Innovation Media Moonshot.

Kohn Rådberg, K., Lundavist, U., Malmqvist, J., \& Hagvall Svensson, O. 2018. From CDIO to challenge-based learning experiences-expanding student learning as well as societal impact?. European Journal of Engineering Education, 1-16.

Kolb, A. Y., \& Kolb, D. A. 2005. Learning styles and learning spaces: Enhancing experiential learning in higher education. Academy of management learning \& education, 4(2), 193-212.

Ozdemir, S. 2017. Basic Technology Competencies, Attitude towards Computer Assisted Education and Usage of Technologies in Turkish Lesson: A
Correlation. International Education Studies, 10(4), 160. 
Ozogul, G. 2018. Best Practices in Engaging Online Learners Through Active and Experiential Learning Strategies. Interdisciplinary Journal of Problem-Based Learning, 12(1), 11.

Robert, S., \& Newsline, L. T. I. 2005. Millennial" learning: on demand strategies for generation $\mathrm{x}$ and bevond. Learning and Training Innovations, December, 14.

Schmidt, R., Möhring, M., Härting, R. C., Reichstein, C., Neumaier, P., \& Jozinović, P. 2015. Industry 4.0potentials for creating smart products: empirical research results. In International Conference on Business Information Systems(pp. 16-27). Springer, Cham.

Surry, D. W., Ensminger, D. C., \& Haab, M. 2005. A model for integrating instructional technology into higher education. British iournal of educational technology, 36(2), 327-329.

Udjaja, Y., Guizot, V. S., \& Chandra, N. 2018. Gamification for Elementary Mathematics Learning in Indonesia. International Journal of Electrical and Computer Engineering (IJECE), 8(6).

Udjaja, Y. 2018. ANDROID APPLICATION FOR DETECTION OF SKIN CANCER USING EXPERT SYSTEM. Social Economics and Ecology International Journal (SEEIJ), 2(1), 1-8.

Udjaja, Y. 2018. Gamification Assisted Language Learning for Japanese Language Using Expert Point Cloud Recognizer. International Journal of Computer Games Technology, 2018.

Yanfi, Udiaia, Y., \& Sari, A. C. 2017. A Gamification Interactive Typing for Primary School Visually Impaired Children in Indonesia. Procedia Computer Science, 116, 638-644.

You, J. W., \& Kang, M. 2014. The role of academic emotions in the relationship between perceived academic control and self-regulated learning in online learning. Computers \& Education, 77, 125-133. 